\title{
The Malaria Threat to the Army in Hong Kong
}

Major A. Henderson, MRCP, RAMC, Consultant Physician

British Military Hospital, Hong Kong, BFPO 1

SUMMARY: Changes in mosquito ecology and active anti-vector measures abolished endemic malaria transmission in Hong Kong by 1969. Unfortunately, endemic transmission of $P$. vivax reappeared in 1977 . The threat posed to the British $\stackrel{\text { ? }}{?}$ Army in Hong Kong however, appears to be small (5 cases since 1983), and restricted to areas close to the border with the $\bar{C}$ Peoples Republic of China. Malaria biology and protective measures are discussed.

\section{Introduction}

The global malaria situation is in a state of flux, necessitating frequent, detailed reappraisals of the malaria threat to the Army in its various areas of operation. The malaria threat in Hong Kong has waxed and waned over the last 30 years. The Colony was formerly malarious, with about 2000 locally acquired cases each year. ${ }^{1}$

Antivector measures undertaken as part of the World Health Organisation global malaria eradication programme, coupled with changes in vector ecology, gradually reduced malaria transmission in the Colony. Endemic transmission ceased totally in $1969^{1}$.

Unfortunately, by 1968 the momentum of the WHO campaign had been lost, and over the last decade, malaria has been advancing everywhere ${ }^{2,3}$. As part of the general deterioration, endemic transmission reappeared in Hong Kong in 1977, and the Colony is now designated as malarious by the Army.

Much however, has been done locally with regard to malaria control, so it would seem timely to review the size of the malaria threat to the Army in Hong Kong.

\section{Climate and Geography}

The Colony of Hong Kong lies between $22^{\circ} 09^{\prime}$ and $22^{\circ} 37^{\prime}$ north latitude and $113^{\circ} 52^{\prime}$ and $114^{\circ} 30^{\prime}$ east longitude. The total land area of $1032 \mathrm{~km}^{2}$ comprises an area of mainland bordering the Kwantung province of southern China, and over 200 off-shore islands, of which Lantau and Hong Kong Island are the largest (see Map I).

Outside the urban areas of Hong Kong Island and Kowloon are large areas of low hills (up to $1000 \mathrm{~m}$ ) covered with scrub. Nearer to mainland China, the topography is flatter, and here slow flowing streams and bodies of fresh water (both natural and man-made) provide ideal mosquito breeding conditions.

The climate is subtropical with two major seasons. Between November and March it is cool and relatively dry, giving conditions unfavourable for malaria transmission. Between April and October however, the weather is hot and humid and ideal for both vector and parasite ecology.

The population according to the 1981 census is a little over 5 million.

\section{Vectors}

About 70 species of mosquito have been described in Hong Kong, of which 11 are Anophelines ${ }^{4}$. Mosquito $\overrightarrow{0}$ numbers have fallen in recent years due to active antivector measures and changes in the environment unfavourable to vector biology (particularly a reduction in rice cultivation and an increase in pollution). The 3 following potential vectors are regularly found in the? colony:

Anopheles bengalensis (Puri 1930). This jungle mosquito has become rare as a consequence of deforestation.

Anopheles fluviatilis (James 1902). Favours streams wifho grassy banks. Although widespread its numbers arenever high.

Anopheles jeyporiensis (Koidzumi 1924). Favours sli़ॄ: moving streams and standing water. It is common and strongly anthropophilic making it a prime potential $\overrightarrow{0}$ vector.

Anopheles karwari (James 1903). Favours swamps a⿳亠口冋d ditches. Although anthropophilic, it is uncommon.

Anopheles lesteri (Baisas and Wu 1939). Favourso grassland where standing water is abundant. It is an $\frac{\mathrm{D}}{\mathrm{D}}$ important vector in southern China and possibly in Hong Kong.

Anopheles maculatus (Theobald 1901). Favours casual water and is zoophilic.

Anopheles minimus (Theobald 1901). Favours hill streams where the water velocity does not exceed $0.1 \mathrm{~m}$ per second. It is anthropophilic and bites indoors. It is a major potential vector.

Anopheles sinensis (Wiedeman 1928). Favours slow lowland streams and rice paddy. Although only weaklyanthropophilic it appears to be an important vector in China.

Anopheles splendidus (Koidzumi 1920). Favours slow lowland streams and rice paddy. It is rare in Hong Kong.

Anopheles tessellatus (Theobald 1901). Favours rice paddy and although common, it is strongly zoophilic.

Anopheles vagus (Donitz 1902). Favours casual, clear̃ water but is uncommon. 
Without doubt, dangerous potential vectors, particularly $A$. minimus and $A$. jeyporiensis, are abundant in Hong Kong. This, plus the climatic conditions during the hot season, render Hong Kong extremely vulnerable to the re-establishment of endemic malaria transmission.

\section{Malaria Epidemiology}

The Colony was rendered malaria-free in 1969 but unfortunately endemic transmission reappeared in 1977. Locally acquired malaria however, represents only a tiny fraction of all the malaria seen in Hong Kong. Imported and endemic malaria will be discussed separately.

Imported Malaria. Hong Kong is very vulnerable to imported malaria as it is surrounded by malarious areas and is a centre of tourism and commerce. The number of cases of imported malaria has been rising steadily over the last decade and reached a total of 162 for 1985 . Exchange visits between the ethnic minorities and malarious areas of India and Pakistan account for $49 \%$ of the cases, while people coming from southern China, especially Shenzhen, account for a further $33 \%$ of all cases. Importantly, about two thirds of imported cases are reported during the summer months when conditions are especially favourable to malaria biology. Of the 162 cases during 1985, 128 were $P$. vivax infections, $19, P$. falciparum, $4 P$. malariae and 11 were mixed $P$. vivax and $P$. falciparum. Since 1983 there have been 49 cases of imported malaria in British soldiers $(1983,8 ; 1984,17 ; 1985,16$; first quarter of 1986,8$)$. Most were acquired in Papua New Guinea (42), the remainder in Nepal (4), Malaysia (2) and the Philippines (1). During $1985,70 \%$ of all imported $P$. falciparum infections were in British soldiers.

Map I

The Colony of Hong Kong

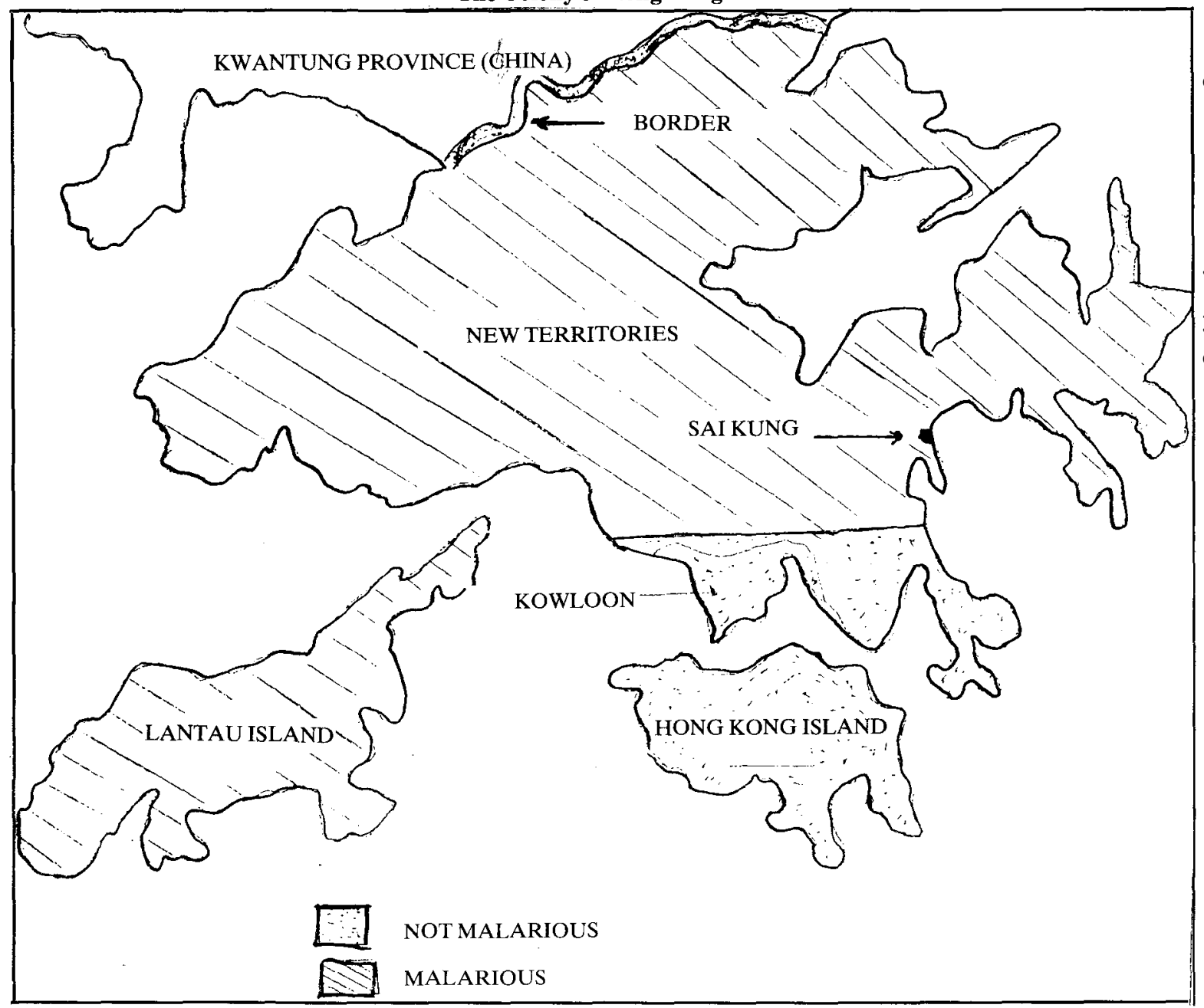


Indigenous Malaria. The prevalence of indigenous malaria is shown in Table I. To date all indigenous infections have been with Plasmodium vivax. There was a significant outbreak in 1983, since when stringent antimalaria measures have been used. Since 1983 there have been 5 cases of indigenous malaria in British soldiers $(1983,3$; 1984, 1; first quarter of 1986, 1). All the soldiers were infected while on duty close to the border with China. There have been no cases recently in British dependants.

\section{Malaria Control Measures}

A) Civilian. The Hong Kong government is actively involved in malaria control. The anti-malaria programme is co-ordinated by a multi-disciplinary committee which includes military representatives.

1) Vector Control. In vector breeding areas, adult mosquitoes are destroyed by the regular use of insecticides dispensed by a swing fog technique. Larvae are controlled by a combination of oiling and chemical larvicides (Abate). The use of non-chemical methods, especially predatory fish and hand sluice flushing of streams, are under investigation.

2) Case Control. Where possible, clinical cases are treated in designated hospitals according to an agreed policy. All patients with falciparum infections receive a gametocytocidal dose of primaquine. Blood film examination is used to detect asymptomatic secondary cases.

Table I

Indigenous Malaria in Hong Kong since 1969

\begin{tabular}{cc}
\hline Year & Number of Cases \\
\hline 1969 & 0 \\
1970 & 0 \\
1971 & 0 \\
1972 & 0 \\
1973 & 0 \\
1974 & 0 \\
1975 & 0 \\
1976 & 0 \\
1977 & 1 \\
1978 & 0 \\
1979 & 0 \\
1980 & 1 \\
1981 & 1 \\
1982 & 1 \\
1983 & 30 \\
1984 & 10 \\
1985 & 3 \\
\hline
\end{tabular}

B) Military

1) Vector Control. Vector control was centralised ink 1985. All potential mosquito breeding areas under military control are visited weekly by environmenta health teams who use a combination of swing fogging and residual insecticide spraying to control adulo vectors. Larval control is effected by preventing the? accumulation of casual water.

2) Personal Anti-Mosquito Measures. Long sleeves and trousers are worn between dusk and dawn where outdoors, and insect repellants, incorporating diethyltoluamide, are used liberally. In sleeping accommodation not fitted with antimosquito mesh, net are used. Sleeping quarters are cleared by a knock-downinsecticide.

3) Personal Chemoprophylaxis. All personnel an $\vec{w}$ dependants working in, living in, or visiting the designated malarious areas (Lantau Islands, Sai Kung Эّ New Territories north of grid-line 77), are required to? use chemoprophylaxis. The Army and Royal Air Forcee use Proguanil in the following daily dosages:

$\begin{array}{lr}\text { Adults and children over } 12 \text { years: } & 200 \mathrm{mg} \\ \text { Children 6-12 years: } & 150 \mathrm{mg} \\ \text { Children 1-5 years: } & 100 \mathrm{mg} \\ \text { Infants: } & 50 \mathrm{mg}\end{array}$

The Royal Navy uses Maloprim one tablet weekly.

Assessing the extent of compliance witt chemotherapy is notoriously difficult. However, as alt proguanil issued to outstations is dispensed from BN\$P Hong Kong, it is possible to compare the expected us (based on the number of military personnel a⿳亠丷⿵冂丶 dependants living in or working in the malarious areas and the known recommended daily dosage) with the actual usage (amount dispensed from BMH Hongo

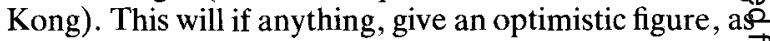
it does not take into account casual visitors anc $\vec{B}$ proguanil issued to, but not used by, outstations. The ${ }^{3}$ actual usage of proguanil as a percentage of the expected is shown in Table II. It is quite clear that compliance is. very poor indeed, and even assuming that all the proguanil issued is used by Military personnel only, the actual annual consumption lies somewhere between one third and one half of the expected consumption.

\section{Conclusions}

The rural areas of Hong Kong are receptive to malari and are dangerously vulnerable during the hot seasoni Under ideal conditions a single infected mosquito cam give rise to as many as 5000 human cases ${ }^{5}$ and althouglo such conditions are unlikely to be met in the field experience from Italy has shown one imported case of malaria can give rise to a minor epidemic ${ }^{6}$. Although numerically, imported cases from the Indian subcontinent seem to pose the biggest threat, in fact most of these patients come from urban areas wher@ 
Table II

Actual Paludrine Consumption as a Percentage of Expected

\begin{tabular}{ccc}
\hline & $\begin{array}{c}\text { Assuming all at } \\
\text { risk } \\
\text { use Proguanil }\end{array}$ & $\begin{array}{c}\text { Assuming only } \\
\text { Soldiers and RAF } \\
\text { Personnel } \\
\text { use Proguanil }\end{array}$ \\
\hline 1984 & $24 \%$ & $32 \%$ \\
1985 & $36 \%$ & $48 \%$ \\
$\begin{array}{c}\text { First } \\
\text { quarter of } \\
1986\end{array}$ & $26 \%$ & $35 \%$ \\
\hline
\end{tabular}

vectors are few. The real threat is from patients infected in China and returning to the rural areas of the Colony, or from British soldiers returning from exercises in malarious areas, to camps in the New Territories. Exercises in Papua New Guinea seem to be especially problematic in this regard ${ }^{7}$. The Army is currently reviewing its malaria prophylaxis policy to reduce this very real threat.

The prevalence of indigenous malaria in the unprotected civilian population is very low and has fallen since 1983 as a consequence of aggressive antimalaria measures. This suggests that the risk to the Army must also be very small, particularly as soldiers take personal antimosquito precautions. It seems the major area of concern is in the zone near by the border with China where men are exposed at night to infected mosquitoes flying in from China. Even here however the risk is relatively small (only 5 cases over the last 3 years). The role of proguanil in effecting protection is probably marginal at best, as non-compliance is so widespread. It is extremely difficult to motivate soldiers, and probably impossible to motivate dependants, to take regular chemoprophylaxis when the perceived (and actual) malaria risk is so low. For those living in, working in or visiting the outlying islands and the New Territories away from the border with China, the malaria risk is very small indeed. Here a combination of community based and personal antimosquito measures, which have been shown to be highly effective in American soldiers in Thailand, would probably be sufficient ${ }^{8}$. For those near the border, although the risk is small, the occurrence of even a few malaria cases justifies the use of chemoprophylaxis. The very low malaria rate and the absence of falciparum infections however, make it difficult to justify the use of any drug with toxic potential. The continued use of proguanil, which is extremely safe, has many attractions ${ }^{9}$. Compliance might be improved by the use of urine testing in a random fashion to detect defaulters.

It must be stressed, at the time of writing, that all personnel and dependants in malarious areas are required to take chemoprophylaxis.

\section{REFERENCES}

1. Paik Y H and Thevasagayan E S. Report of a field visit to Hong Kong, December 7-14, 1983. WHO 1983.

2. BRUCE-ChwATT L J. Man against malaria: conquest or defeat. Trans R Soc Trop Med Hyg 1973; 73:605-617.

3. FAID M A. The malaria programme - from euphoria to anarchy. World Health Forum 1980; 1:8-22.

4. ChaU G W. An illustrated guide to the identification of the mosquitoes of Hong Kong. Pub. Hong Kong Urban Council. 1982.

5. MacDonald G. Community aspects of immunity to Malaria. Br Med Bull 1951; 8:33-36.

6. Zulueta J De. Report on a visit to Italy from 11-22 March 1951. WHO. Geneva.

7. Henderson A, et al. Polyresistant malaria in Gurkha soldiers returning from Papua New Guinea: treatment and prevention. J R Army Med Corps 1986; 132:37-41.

8. WINTER P E, et al. Malaria discipline as prophylaxix. Milit Med 1967; 132:917-919.

9. RHODES F A. The toxicity of anti malarial drugs. Papua New Guinea Med J 1974; 17:88-92.

\section{NOTE FROM DEFENCE MEDICAL SERVICES DIRECTORATE \\ Malaria - Preventive Strategies}

The intermittent dispersal, to malarious areas, of service personnel and dependants for garrison duty, exercises, Loan Service or more importantly operations, calls for an anti-malaria strategy. For reasons that will be obvious to the reader the simpler the strategy the more likely it is to succeed, and certainly complicated procedures are to be avoided if contingency plans for operations are envisaged.

Service policy has, for years, been based on three? simple principles: reducing to the minimum the chance of being bitten by the malaria-carrying mosquito, reducing the mosquito population, and chemoprophylaxis.

In the civilian sphere since the early sixties for a multitude of reasons a whole range of chemoprophylaxis has been offered to the unsuspecting traveller. Many and varied have been the authoritative pronouncements on the appropriateness or otherwise of some drug regime. The result has been chaos and confusion, so much so that of recent date a meeting of experts was convened in London to attempt to simplify and coordinate chemoprophylaxis advice. After much debate and discussion a simple to understand and simple to follow chemoprophylactic regime for UK based travellers has been agreed and will be published in due course.

During this confused period the Services have, to the best of their ability, resisted the temptation to try some variant chemoprophylactic and have retained, principally, the simple and generally safe and effective regime of daily Proguanil as our main chemoprophylactic. On the whole this policy has not failed us; such 
problems as we have had can almost without exception be laid at the door of poor compliance, not failure of drug regime.

For some years now there has not been an authoritative service instruction on this matter but as we were much involved in the aforementioned civilian discussions it seemed proper to review our time-expired Defence Council Instructions (DCI) and reissue. The resultant $\mathrm{DCI}$, which takes account of the civilian

\section{FROM EMR POLICY LETTER 18/86}

\section{Chemoprophylaxis}

12. Service personnel and their dependants will take anti-malarial drugs whilst in malarious areas. Failure to take antimalarials is the commonest cause of breakdown of an anti-malarial programme. It is important to remember, however, that no drug offers complete protection from this disease.

13. The standard anti-malarial drugs are chloroquine and proguanil (Paludrine), taken in combination. This combination of drugs is the safest and most effective for Service purposes worldwide.

14. For the present the only alternative regimes are for personnel under the medical jurisdiction of Commander Medical, Hong Kong, where, in decisions as the constraints of service life, is now in the pipeline and has been distributed on the medical net to 3 all Commands under cover of a policy letter, so all should already have had a chance to read it.

The DCI is of course addressed to a lay audience and states much which is basic; however for ease of referenceo the paragraphs relating to chemoprophylaxis areen recorded below-

accordance with local instructions, chemoprophylaxis $\stackrel{\varnothing}{\varrho}$ will be with proguanil alone. Adult personnel travelling to Papua New Guinea will take proguanil and dapsone. $\overrightarrow{0}$

15. On the very rare occasion that some other chemoprophylaxis is required, units or individuals are $\vec{\omega}$ to seek guidance through normal service medical channels from the Defence Medical Services Directorate (EMR 2a).

\section{Dosage of malaria prophylactic drugs.}

16. Standard regime

Adults and children over 12 years

Proguanil $200 \mathrm{mg}$ (ie 2 tablets) daily

plus

Chloroquine $300 \mathrm{mg}$ base (ie 2 tablets) weekly

\begin{tabular}{|c|c|c|c|c|c|}
\hline Children & dose & Proguanil & daily & Chloroquine & weekly \\
\hline $0-8$ weeks & $(1 / 8)$ & $25 \mathrm{mg}$ & (1/4 tablet) & $37.5 \mathrm{mg}$ & (1/4 tablet) \\
\hline 2-11 months & $(1 / 4)$ & $50 \mathrm{mg}$ & (1/2 tablet) & $75 \mathrm{mg}$ & (1/2 tablet) \\
\hline $1-5$ years & $(1 / 2)$ & $100 \mathrm{mg}$ & (1 tablet) & $150 \mathrm{mg}$ & (1 tablet) \\
\hline 6-11 years & $(3 / 4)$ & $150 \mathrm{mg}$ & (11/2 tablet) & $225 \mathrm{mg}$ & (11/2 tablet) \\
\hline
\end{tabular}

When proguanil is taken alone the doses remain as shown.

For Papua New Guinea adult prophylaxis will be

proguanil $200 \mathrm{mg}$ daily

plus

dapsone $100 \mathrm{mg}$ weekly

17. Antimalarials must be started one week before arriving in a malarious area and must be continued for four weeks after leaving. 